DOI: 10.17805/zpu.2015.2.11

\title{
Коренные народы Сибири: могут ли они ответить на вызовы XXI века?*
}

\author{
У. А. ВИнОКУРОвА
}

(АРКТИЧЕСКИЙ ГОСУДАРСТВЕННЫЙ ИНСТИТУТ КУЛЬТУРЫ И ИСКУССТВ, Г. ЯКУТСК)

Статья посвящена актуальной теме перспектив исторической судьбы народов Сибири на территории России от Урала до Тихого океана. Эта территория является местом исконного проживания современных коренных и коренных малочисленных народов Севера, Сибири и Дальнего Востока, для которых в современных условиях с особой остротой стоят вопросы сохранения этнокультурной целостности и идентичности, традиционных видов природопользования.

С 2001 по 2014 г. автором проведены полевые исследования на территориях республик Саха (Якутия), Бурятии, Горного Алтая и Хакасии, Иркутской, Кемеровской и Томской областей, Ямало-Ненецкого автономного округа. Применялись функционально-системный подход и методы включенного наблюдения и интервью с представителями национальной интеллигенции и этнофорами саха, бурят, шорцев, алтайцев, хакасов, тувинцев,

* Подготовлено по проекту 2.7.4. «Современные междисциплинарные исследования Северо-Востока России» (в рамках договора между Северо-Восточным федеральным университетом им. М. К. Аммосова и Кембриджским университетом, Великобритания).

Prepared as part of the project 2.7.4 "Contemporary Interdisciplinary Research of the North-East of Russia" (according to the agreement between M. K. Ammosov North-Eastern Federal University and the University of Cambridge, UK). 
ненцев, юкагиров, эвенов, эвенков. На основе проведенного исследования предлагается выделить три уровня этносоциальных последствий трансформации политики федерального центра по отношению к народам Сибири: личностный, этнополитический, этнокультурный. Выявлены пять моделей стратегии выживания народов Сибири: неотрадиционализм, соуправление, конкурентная стратегия, вытеснение коренных народов, народосбережение.

Заключается, что большинство сибирских народов не имеют достаточных шансов на воспроизводство своей коллективной идентичности как этнической общности собственными силами. Этничность исчезающих народов подвергается всевозможным влияниям и факторам разрушения. Народы Сибири могут получить шанс на сохранение только при условии внедрения и реализации международного права коренных народов в правовом пространстве России.

Ключевые слова: Сибирь, Дальний Восток, коренные народы, этнические ценности, этногенные процессы, архаизация, неотрадиционализм, самоуправление, модели выживания, народосбережение.

\section{ВВЕАЕНИЕ}

$\mathrm{B}$ климатическом плане Сибирь - территория России от Урала до Тихого океана считается зоной дискомфортности для населения. Наиболее дискомфортные территории расположены в Арктике восточнее Енисея и в восточной, северной Якутии, где максимальный показатель достигает 42,95 балла из 100 (Мартынов, Виноградов, 1998: Электр. ресурс). Между тем Якутия отличается значительной долей стабильного коренного населения. В целом Сибирь представляет образец очевидного несоответствия между размерами территории и численностью населения. Эта азиатская часть России, составляющая 13119,6 тыс. км², т. е. 76,7\% территории российского государства (Россия: федеральные округа и регионы ... , 2006/2007: 360, 402, 476), где в трех федеральных округах проживает 38 182,1 тыс. чел., т. е. 26,1\% всего населения.

Принято считать, что ценность территории определяется уникальным богатством ее недр. Сибирь имеет устойчивый имидж «кладовой страны». Кроме того, Сибирь как мегарегион долго определялась как российская колония, торгово-транспортный путь, соединяющий континент Евразии, инновационная кузница и дом родной для сибиряков и коренных народов (Суслов, 2014).

Функционально-системный подход к изучению скорости эволюции народов Сибири позволяет выделить этногенные процессы - процессы, происходящие на уровнях биосферы, социосферы и этносферы. Сохранение устойчивости (стабильности) и структурной перестройки адаптационных механизмов коренных народов в ответ на вызовы среды зависит от ддинамики ландшафтогенных процессов (Балзер-Мандельштам, 2014). В Сибири обнаруживается сильное влияние географического ландшафта на социосферу и этносферу коренных народов. Аандшафтно-географический фактор представляет собой изменение среды обитания в силу как природных, так и антропогенных процессов (последние изменяют параметры среды обитания, выражаются в активном преобразовании природного ландшафта горнодобывающей промышленностью, что привело к нарушению геобиоценоза флоры и фауны).

Эндогенные процессы у народов Сибири имеют комплексный характер, что выходит за рамки таких конфигураций межкультурных взаимодействий, как аккультурация, ассимиляция, этноцид, культурные диффузия и партикуляризм, империализм, релятивизм и толерантность. Аело в том, что поиск ответа на вынесенный в заглавии статьи вопрос осуществляется через призму indigenous metbodology - методологии для определения особенностей образа жизни народов, сложившихся в определенных условиях жизнеобеспечения. 
Сибирь является исконной землей, домом родным аборигенных народов, численность и расселение которых остается на периферии государственной политики по отношению к хозяйственному освоению сибирских недр и природных богатств. Так, в Федеральном законе от 29 декабря 2014 г. № 473 «О территориях опережающего социально-экономического развития в Российской Федерации» (Федеральный закон ... , 2014: Электр. ресурс) за коренными народами Севера, Сибири и Аальнего Востока и их административно-территориальными образованиями не установлены правовые нормы государственного протекционизма при создании территорий опережающего развития на территориях их традиционного расселения. Как полагает В. К. Заусаев, можно говорить о «выдавливании» экономики на Север, усилении сырьевой специфики и сокращении постоянного населения. Аоводя эти тенденции до логического конца, можно ожидать, что сокращение численности продолжится, станет реальностью передача отдельных территорий региона в долгосрочную аренду (концессию) сопредельным странам со всеми вытекающими отсюда геостратегическими последствиями (Заусаев, 2014). Проблемы коренных народов Сибири воспринимаются чаще всего как земельные притязания коренных народов, как проблемы территорий и природных ресурсов, которые определяют высокий уровень конфликтности социальных интересов в обществе. Однако, на наш взгляд, приоритетными задачами исследователей является содействие осознанию коренными народами собственных проблем, связанных с формированием и развитием этничности, поиском ответов на вызовы современности (Балзер-Мандельштам, 2014).

Какие модели жизнеобеспечения коренных сибирских народов формируются в современных условиях? В поисках ответа на этот вопрос автор статьи объездила в 2001-2014 гг. территории республик Саха (Якутия), Бурятия, Горный Алтай и Хакасия, Иркутскую, Кемеровскую и Томскую области, Ямало-Ненецкий автономный округ, где провела включенное наблюдение и записала ряд интервью с представителями национальной интеллигенции и этнофорами саха, бурят, шорцев, алтайцев, хакасов, тувинцев, ненцев, юкагиров, эвенов, эвенков.

\section{РЕГИОНААЬНАЯ ИАЕНТИЧНОСТЬ КОРЕННЫХ НАРОАОВ СИБИРИ}

Территория Сибири является местом исконного проживания с незапамятных времен современных 40 коренных малочисленных народов Севера, Сибири и Аальнего Востока, численностью не превышающих 50 тыс. человек, - список этих народов утвержден постановлением Правительства РФ от 24 марта 2000 г. № 255. Кроме них существуют коренные народы, численных которых превышает 50 тыс., такие как саха, буряты, алтайцы, хакасы, тувинцы, их общая численность около 1 млн человек. 3десь не учитывается численность метисного, русского и иного старожильческого населения, в течение нескольких веков укоренившегося на просторах Сибири.

Многократные акты по переселению подданных и граждан России, СССР и РФ для освоения сибирских просторов привели к появлению особой идентичности ее населения - так называемых сибиряков. Назвали себя сибиряками 7,5\% опрашиваемых жителей Сибири (Суслов, 2014: 89). По утверждению А. О. Бороноева, сибирская ментальность характеризуется особым сочетанием культурных традиций, верований и опыта различных народов и имеет два проявления: ментальность русских (и других) старожилов и ментальность сибирских аборигенных народов (Бороноев, 2006: 41). Писатель В. Г. Распутин описывает тип сибиряка русского происхождения с азиатскими чертами в физическом облике и азиатским влиянием в психическом складе. 
Развиваясь на сибирских просторах и народной вольнице, сибиряк, получившийся от слияния славянской порывистости и стихийности с азиатской природностью и самоуглубленностью, приобрел такие черты, как острая наблюдательность, чувство собственного достоинства, упорство, упрямство и укоренность на этой земле. В Сибири никогда не было крепостного права, благодаря чему, по мнению В.Г. Распутина, в сибиряке сохранились лучшие качества русских. Образ сибиряка сформировался в соответствии с природой Сибири - порывистость и оцепенелость, откровенность и затаенность, яркость и сдержанность, щедрость и сокрытость - это есть Сибирь, ее «огнеупорный» дух. «Радеть о счастливо доставшейся земле - задача сибиряка нового», - считает В. Г. Распутин (Распутин, 2008: 330).

ОАним из очевидных противоречий сибирской идентичности становится отношение к природе: с одной стороны, усиливается экософское мировоззрение ценностного отношения коренных народов к природе, с другой - происходит разрушение природы в целях добычи ее ресурсов.

Основой сибирской ментальности является исходная культура коренных народов, освоивших различные биосферы Сибири. Активное обсуждение исторических судеб предков, имеющих кровно-родственные связи с коренными народами Сибири, усиление территориальной идентичности и формирование художественной картины мира в соответствии с геокультурным сибирским ландшафтом становятся основными направлениями трансформации ценностей постсоветского сибиряка.

Издавна Сибирь была открыта межэтническим коммуникациям, миграциям коренных кочевых этнических общностей, осваивающих соответствующие их хозяйственно-культурному укладу биосферы кормящего ландшафта. Особенность их образа жизни в отличие от жизнедеятельности оседлых народов состояла в том, что для них биомасса гумуса была не столь важна. Коренные народы Сибири выработали стратегии жизнеобеспечения ресурсами моря и суши за счет потребления таких видов биосферы кормящего ландшафта моря и суши, как нектон (совокупность океанских животных) и биомасса животных на суше. Арктическое оленеводство стало одним из эффективных механизмов ответа на вызов суровых земель, получив распространение на побережье арктического и субарктического циркумполярного региона. Особенно отличились ненцы, покрывшие оленьими стадами арктические просторы Евразии, а также эвенки, ныне имеющие места компактного проживания на территории пяти субъектов Российской Федерации, районов в Китае и Монголии. Экстратерриториальные сообщества имеют также буряты-скотоводы, проживающие на территории трех субъектов РФ, а также Монголии. Стратегию жизнеобеспечения ресурсами моря демонстрируют эскимосы, освоившие почти полный круг Арктического океана - Гренландию, Аляску (США) и Чукотку (Сибирь, Россия).

\section{ЭТНОСОЦИААЬНЫЕ ПОСАЕАСТВИЯ СОЦИААЬНО-ТРАНСФОРМАЦИОННЫХ ПРОЦЕССОВ В РЕГИОНАХ СИБИРИ}

В настоящее время сибирские коренные народы вырабатывают новые модели выживания в ответ на глобальные и российские геополитические вызовы. Академик В. А. Тишков отмечает: «В целом политика по отношению к насельникам Арктики долгое время была подчинена утилитарным экономическим интересам, идеологическим установкам и военно-стратегическим расчетам. Таковой она остается во многом и поныне... <..> Мы не видим в среднесрочной перспективе каких-либо драматических демографических изменений среди этой части российского населения, и тем более нет оснований ожидать, что возникнет какая-то обширная административная 
территория с преобладанием представителей арктических групп, как, например, это произошло в Канаде и привело к образованию новой автономной территории Нунавут с преобладающим проживанием канадских аборигенов» (Тишков, 2014: Электр. ресурс).

Процесс трансформации Советского государства в современную Россию оказывает сильнейшее влияние на отношение коренных народов к своей этнической идентичности. Оно проявилось во время Всероссийской переписи населения России в том, что обнаружилось явное несоответствие между резким уменьшением демографического воспроизводства этносов в однонациональных браках и возрастающей численностью количества представителей этносов с соответствующей этнической идентичностью.

Преимущественно негативная демографическая динамика была отслежена российским демографом А. Богоявленским из Института демографии НИУ ВШЭ, который сравнил демографическое состояние коренных малочисленных народов Севера, Сибири и Аальнего Востока по данным Всероссийских переписей населения 1989-2010 гг. (Богоявленский, 2004, 2012). Мы предлагаем выделить три уровня этносоциальных последствий социальной трансформации страны, которые отразились на народах Сибири: первый - личностный, второй - этнополитический, третий - этнокультурный.

На первом уровне, личностном, отмечается отход представителя коренного народа от этнокультурной стратегии традиционного жизнеобеспечения. Это сопровождается нарушениями механизмов этнического жизнеобеспечения, проявляющихся в следующих видах:

- исход за пределы своего биохора, смена образа жизни, что приводит к перемещению в города, люмпенизации, превращению некоторых их них в аутсайдеров общества;

- традиционный механизм жизнеобеспечения попадает под государственный контроль, разделяющий представителей этносов на проживающих в местах традиционного расселения и выехавших за их пределы (тем самым лишившихся предусмотренных преференций по традиционным видам промысла);

- установление правового статуса исконных земель в виде федеральной собственности приводит к их отчуждению от родовых угодий, утере легитимной возможности применять установленные охранительные меры по отношению к кормящему ландшафту исконной земли предков;

- установления федеральных органов, уполномоченных определять правовые основы использования водных биологических ресурсов, не основываются на традиционных механизмах жизнеобеспечения коренных народов, не учитывают особенности традиционного природопользования.

Второй уровень - активизация этнополитической субъектности. Во-первых, она происходит в форме общественных объединений, из которых самой крупной является Ассоциация коренных малочисленных народов Севера, Сибири и Аальнего Востока, созданная в 1990 г. и объединяющая 34 региональных и этнических образования. Предпосылки создания Ассоциации ее президент С. Н. Харючи сформулировал следующим образом: «Национальная интеллигенция народов Севера в 1970-1980-е годы с горечью наблюдала за утратой национальной культуры и языков, трансформацией традиционного уклада жизни, ухудшением морального и физического здоровья северян» (Харючи, 2010: Электр. ресурс). В годы перестройки об этом громко заговорили прежде всего писатели коренных народов - Еремей Айпин, Владимир Санги, Юрий Рытхэу, Юван Шесталов, Алитет Немтушкин, ученые из числа коренных народов - 
Евдокия Гаер, Чунер Таксами, Василий Роббек. Их поддержали многие специалисты, изучавшие коренные народы: этнографы, медики, педагоги и др. Переосмысление и переоценка ценностей для представителей коренных народов Сибири стали фактором социокультурной мобилизации и создания общественных объединений для защиты своих интересов.

Во-вторых, создание национально-административных и национально-государственных образований в структуре российского федеративного государства на основе Федеративного договора от 31 марта 1992 г., содержащего Аоговор о разграничении предметов ведения и полномочий между федеральными органами государственной власти Российской Федерации и органами власти суверенных республик, а также органами власти автономной области, автономных округов в составе Российской Федерации. На основе этого Федеративного договора образована своеобразная иерархия народов посредством их этнополитической дифференциации, состоящей из трех «матрешек»: национально-административные образования в виде республик, в п. 2 ст. 5 Конституции РФ приравненных по статусу к государству и названных именами так называемых титульных народов (саха, буряты, алтайцы, хакасы, тувинцы); затем следуют национально-территориальные образования - самостоятельные или в составе субъекта РФ (Ямало-Ненецкий автономный округ, Ханты-Мансийский автономный округ, Эвенкийский национальный округ, Чукотский автономный округ, Таймырский (Аолгано-Ненецкий) автономный округ). Аля остальных народов могут быть созданы в местах их исконного проживания национальные районы и села. Так, в Республике Саха (Якутия) созданы национальные районы и села эвенов, эвенков, долган и юкагиров.

Анализ эволюции ресурсов самоуправления народов Сибири обнаруживает историческое изменение социальной и национальной политики вмещающего государства и сложившихся цивилизаций, которые входят в культурный мир государства. Отмечается неизменность модели власти Российской империи - СССР - РФ в виде разной степени тоталитаризма и диктаторства по отношению к национальным меньшинствам, стремящихся к контролю за своей судьбой. Главным рычагом сдерживания самоуправления становится контроль государства над экономическими ресурсами территорий и самообеспечения населения. Общая динамика капиталовложений для сохранения традиционного уклада отсутствовала или была минимальной. Нет целевых индикаторов жизнеобеспечения и развития коренных народов Сибири в Стратегии социально-экономического развития Сибири до 2020 г., утвержденной распоряжением Правительства Российской Федерации от 5 июля 2010 г. № 1120-р.

Третий уровень этносоциальных последствий - этнокультурный. Начало постсоветского периода характеризовалось развертыванием процессов этнокультурного возрождения, или возрождения национальных культур. Наиболее ярко он проявляется в сакральных для местного населения местах. Создаются музеи, посвященные местным народностям, туристические маршруты, этнокультурные центры в местах кочевья и этногенеза народов Сибири. Наблюдается сложный процесс интеграции сибирских народов, осознающих общность судеб, и их внутренней дифференциации этнических локальных общностей. При этом идет поиск эффективных механизмов этнокультурного воспроизводства идентичности, этнического самосознания. Проведение Ёрдынских игр на Байкале, различных солидаризующих фестивалей этнических культур, организация сугуланов тюркской молодежи, восстановление памяти хакасского культурного героя Сартыкбая, возрождение алтайской религии «ак дьян»все это и многое другое свидетельствует о мобилизации этнокультурных традиций народов как факторов этнической мобилизации. 
Принятие деклараций о государственном суверенитете национальных республик народов саха, бурят, тувинцев, алтайцев стало сильным стимулом для мобилизации этничности в самоуправлении. Здесь произошло рекрутирование национальной интеллигенции из сфер науки, техники, экологии, культуры и искусства в государственную власть и самоуправление. Аля некоторых малочисленных этносов и локальных групп титульных народов конструирование этничности малочисленного народа стало оцениваться как способ адаптации к рыночным отношениям. Так, некоторые алтайские этносы, северные саха, русские старожилы, камчадалы, шорцы хотели получить статус малочисленного коренного народа, чтоб остаться в поле протекции государства.

Среди негативных тенденций можно отметить перенесенную с советских времен культурную травму, которая сегодня стала углубляться в связи с воздействием вестернизационных ценностей, глобализационных влияний, при котором подвергаются дальнейшему разрушению традиционные элементы идентичности. Это чревато обеднением культурного капитала этносов Сибири. В целом по регионам постсоветского пространства распространились процессы архаизации, о чем пишет Ч. К. Аамажаа, демонстрируя их наиболее яркие формы на примере Республики Тыва (Тувы). Они выразились в стихийном возврате к древним (архаическим) пластам культуры и социальных отношений, натурализации хозяйственной деятельности, усилении дистанцированности между социальными группами, религиозности населения, межэтнической нетерпимости, клановости (Мамажаа, 2011).

\section{СОВРЕМЕННЫЕ МОАЕАИ ВЫЖИВАНИЯ НАРОАОВ СИБИРИ}

В целом можно условно выделить пять моделей стратегии выживания народов Сибири, исходя из роли и места коренных народов в органах власти, в формировании стратегии социального развития и пр.

Первая модель - неотрадичионализма во всех сферах социальной жизни (Попков, Костюк, Тюгашев, 2007; Ааргын-оол, 2003; Аамажаа, 2010). Неотрадиционализм трактуется исследователями как стратегия адаптации к современным условиям, опирающаяся на культурные традиции этносов, позволяющая им сохранять и развивать этнокультурную идентичность и быть активным участником социальных, экономических, политических изменений. Аанная модель опирается на вековые традиции и открывает сценарий-тренд модернизации с сохранением культурной идентичности $(\Lambda а-$ мажаа, 2011).

Вторая модель - соупраљления. Ее можно наблюдать с определенной долей условности в ряде регионов, например в Республике Саха (Якутия). Ее суть заключается в существовании органов самоуправления во всех трех ветвях государственной власти, где преобладают представители коренных народов. Эта модель распространена в Канаде и Скандинавских странах. В Республике Саха выработана законодательная база, защищающая традиционные ценности коренных народов Якутии.

Третья модель - конкурентная. Эта модель характерна для Республики Бурятия. Она выражается в конкуренции между представителями бурятской и русской культур в различных областях социальной жизни: политической, экономической, культурной. Аанная модель укоренилась на территории республики и держится в течение четырех веков. Благодаря поддержке русского правительства в имперские времена доминирование русской культуры было обеспечено. В советские времена удавалось придерживаться политики баланса, в постсоветское время ситуация изменилась. Бурятская 
идентичность активизировалась в ходе процессов национального возрождения по всей стране.

Четвертая модель - вытеснение коренных народов. Эта модель распространена на благодатных территориях исконных земель многих коренных и малочисленных народов Сибири, особенно в республиках Алтай и Хакасия. Проявляется в захвате пастбищ, территорий вдоль берегов Катуни, знаменитых озер, долин различными юридическими и физическими лицами, занятыми туристско-рекреационными видами деятельности. При строительстве новых зон отдыха используется алтайская цветовая и архитектурная символика, мифологические образы как привлекательные турпродукты, но собственно алтайская культура не выдерживает натиска европейского стиля природопользования. В создавшихся условиях алтайская интеллигенция сосредоточилась на сохранении духовных ценностей, связанных с алтайскими горами, прародиной тюрков, восстановлении традиционной религии, памяти Г. И. Чороса-Гуркина как основателя алтайской государственности, создании особо охраняемой природной территории «Каракольский этноприродный парк “Уч-Энмек” (Мир заповедной природы Алтая, 2009).

Пятая модель - народосбережения, элементы которой обнаруживаются в ЯмалоНенецком автономном округе Уральского федерального округа, находящегося на границе Европы и Азии, одного из наиболее богатых и динамично развивающихся на территорий России. За последние 10 лет численность населения округа увеличилась почти на 40 тыс. человек. Ямал входит в первую десятку регионов России по уровню рождаемости. Пришлое население здесь стремится обустроиться на постоянное жительство, чему способствуют не только высокие заработки, ускоренное и масштабное строительство социально-бытовых объектов, но и региональная политика по формированию самосознания северян. Салехард - центр Ямало-Ненецкого автономного округа - строится с учетом особенностей арктической природы и украшается символами ненецкой культуры. Живая культура ненцев, кочевых оленеводов, сохраненная в советское время благодаря отсутствию промышленного освоения, в настоящее время с большим опозданием по сравнению с другими арктическими народами встретилась с иной доминирующей культурой. За последние 20 лет выросла ненецкая национальная интеллигенция, воспитанная на ценностях прав коренных народов и национального достоинства. Аействует общественное экологическое движение «Ямал потомкам», объединяющее всех, кто исповедует экософские ценности независимо от национальной принадлежности.

Однако все эти модели не решают основных проблем народов Сибири, сформу-лированных лидером Ассоциации коренных малочисленных народов Севера ненцем С. Н. Харючи:

- отсутствие четко сформулированной государственной политики в отношении коренных народов;

- отсутствие механизмов реализации прав коренных малочисленных народов Севера на возмещение убытков, полученных в результате причинения ущерба исконной среде обитания и традиционному образу жизни от деятельности физических и юридических лиц (Харючи, 2013: Электр. ресурс).

\section{ЗАКАЮЧЕНИЕ}

Современная переходная ситуация в России связана с выходом из советского суперцикла в цивилизационной динамике, усложняющейся колебаниями в цивилизационно-культурном пространстве Восток - Запад. Большинство сибирских народов не 
имеют достаточных шансов на воспроизводство своей коллективной идентичности как этнической общности собственными силами. Этничность исчезающих народов подвергается всевозможным влияниям и факторам разрушения. Народы Сибири могут получить шанс на сохранение только при условии внедрения и реализации международного права коренных народов в правовом пространстве России.

Именно взгляд из Сибири наполняет реальным смыслом изречение М. В. Аомоносова «Могущество России будет прирастать Сибирью», в котором ядро развития российской цивилизации видится в Сибири. Это осознает и нынешняя власть. Так, по словам Председателя Правительства РФ А. А. Медведева, «развитие Сибири и Аальнего Востока означает развитие всего российского государства, а не отдельной его географической составляющей» (XIII инвестиционный форум ..., 2014: Электр. ресурс).

\section{СПИСОК АИТЕРАТУРЫ}

Балзер-Мандельштам, М. (2014) Коренные Космополиты. Экологическая защита и активизм в Сибири и на Аальнем Востоке // Культура Арктики / под общ. ред. У. А. Винокуровой. Якутск : Изд. дом СВФУ. 344 с. С. 58-77.

Богоявленский, А. (2004) Вымирают ли народы Севера? [Электронный ресурс]// Население и общество. № 83. Август. URL: http://demoscope.ru/acrobat/ps83.pdf [архивировано в WebCite] (дата обращения: 08.02.2015).

Богоявленский, А. (2012) Аанные Всероссийской переписи 2010 [Электронный ресурс] // Ассоциация коренных малочисленных народов Севера, Сибири и Аальнего Востока Российской Федерации. URL: http://raipon.info/peoples/data-census-2010/data-census-2010.php [архивировано в WebCite] (дата обращения: 08.02.2015).

Бороноев, А. О. (2006) Сибирский менталитет как территориально-региональная форма субъективности // Сибирская ментальность и проблемы социокультурного развития региона : сб. докладов Всерос. науч.-практ. конф., 5-6 июля 2006 г. Улан-УАэ : Изд-во ВСГТУ. Т. 1. 261 c. C. $40-45$.

Ааргын-оол, Ч. К. (2003) Культура как основа социального развития регионов России (на примере Тувы) // Гуманитарные науки в Сибири. № 3. С. 40-43.

Заусаев, В. К. (2014) Аальний Восток России: бросок в глобализацию или государственный патернализм? // ЭКО : всерос. экон. журнал. № 3 (477). С. 105-114.

Цамажаа, Ч. К. (2010) Архаизация, традиционализм и неотрадиционализм // Знание. Понимание. Умение. № 2. С. 88-93.

Мамажаа, Ч. К. (2011) Тува между прошлым и будущим. 2-е изд., испр. и доп. СПб. : Алетейя. $368 \mathrm{c}$.

Мартынов, А. С., Виноградов, В. Г. (1998) Комфортность кдимата [Электронный ресурс] // Web-Атлас: «Окружающая среда и здоровье населения России». URL: http://bio.krc.karelia.ru/ $\mathrm{misc} / \mathrm{atl} / \mathrm{ra25a.htm} \mathrm{[архивировано} \mathrm{в} \mathrm{WebCite]} \mathrm{(дата} \mathrm{обращения:} \mathrm{08.02.2015).}$

Мир заповедной природы Алтая (2009) : учеб. пос. для 8-9 классов / под ред. Р. В. Опарина. Горно-Алтайск ; Барнаул : Фонд устойчивого развития Алтая ; ARTИКА. 156 с.

Попков, Ю. В., Костюк, В. Г., Тюгашев, Е. А. (2007) Народы Сибири в социокультурном пространстве Евразии: ценностные предпочтения и межэтнические установки // Социологические исследования. № 5. С. 62-69.

Распутин, В. Г. (2008) Земля у Байкала = Baikal Land. Иркутск : Сапронов. 415 с.

Россия: федеральные округа и регионы (география, недра, история, население, религия, власть, экономика, социальная сфера, достопримечательности, стратегия развития) (2006/2007) : энциклопедия / под науч. ред. М. А. Севрука. 4-е изд., изм. и доп. М. : Междунар. ун-т «Содружество». 529 с.

Суслов, В. И. (2014) Имиджи Сибири: экономика с историческим уклоном // Регион: экономика и социология. № 1 (81). С. 86-103. 
Тишков, В. А. (2014) Коренные народы российской Арктики: история, современный статус, перспективы : доклад на Общем собрании РАН 16 декабря 2014 г. [Электр. ресурс]// Институт этнологии и антропологии РАH. 22 декабря. URL: http://iea-ras.ru/index.php?go=News\&in= view\&id=528 [архивировано в WebCite] (дата обращения: 08.02.2015).

Харючи, С. Н. (2013) VII съезд коренных малочисленных народов Севера, Сибири и Аальнего Востока Российской Федерации: жизнь, заботы и надежды наших народов (г. Салехард, 28-29 марта 2013 г.) [Электр. ресурс]// Ассоциация коренных малочисленных народов Севера, Сибири и Аальнего Востока Российской Федерации. URL: http://raipon.info/about/Doclad.doc. pdf [архивировано в WebCite] (дата обращения: 08.02.2015).

Федеральный закон Российской Федерации от 29 декабря 2014 г. № 473-Ф3 «О территориях опережающего социально-экономического развития в Российской Федерации» (2014) [Электр. ресурс]// Российская газета. Федеральный выпуск № 6571. 31 декабря. URL: http://rg. $\mathrm{ru} / 2014 / 12 / 31 /$ territorii-dok.html [архивировано в WebCite] (дата обращения: 08.02.2015).

XIII инвестиционный форум «Сочи-2014» (2014) [Электронный ресурс] // Правительство PФ. 19 сентября. URL: http://government.ru/news/14835/ [архивировано в WebCite] (дата обращения: 17.01.2015).

Аата поступления: 12.02.2015 2.

\section{CAN INDIGENOUS PEOPLES OF SIBERIA \\ STAND UP TO THE CHALLENGES OF THE 21ST CENTURY? \\ U. A. VINOKUROVA \\ (ARCTIC STATE INSTITUTE OF ARTS AND CULTURE, YAKUTSK)}

The article is devoted to the topical issue of development prospects for the peoples of Siberia throughout the vast stretch of Russian territory from the Urals to the Pacific Ocean. It incorporates the ancestral lands of many contemporary indigenous and minority peoples of the North, Siberia and the Far East. For them, the issues of preservation of ethnic and cultural integrity, identity and traditional ways of land use are very urgent at the moment.

Since 2001 the author has been conducting field research in the Republics of Sakha (Yakutia), Buryatia, Gorny Altai and Khakassia, Irkutsk, Kemerovo and Tomsk oblasts and the Yamal-Nenets Autonomous District. We have employed the functional-systemic approach, the method of participant observation and conducted interviews with representatives of the national intelligentsia and other individuals from Sakha, Buryat, Shor, Altai, Khakas, Tuva, Nenets, Yukagir, Even and Evenki ethnic groups. Having analyzed the research outcomes, we suggest there are three levels of ethnosocial consequences of transforming the federal policy on the peoples of Siberia: personal, ethnopolitical and ethnocultural. We have also singled out 5 models of survival strategies for the peoples of Siberia: neo-traditionalism, shared governance, competitive strategy, displacement of indigenous peoples, and preserving peoples.

The author concludes that the majority of the peoples of Siberia do not have enough opportunity to reproduce their collective ethnic identity on their own. Ethnicity of endangered peoples is affected by various influences and destructive factors. The peoples of Siberia can get a chance for preservation only if the international rights of indigenous peoples are introduced and implemented in the Russian legislation.

Keywords: Siberia, Far East, indigenous peoples of Siberia, ethnic values, ethnogenic processes, archaism, neo-traditionalism, shared governance, models of survival, preservation of peoples.

\section{REFERENCES}

Balzer-Mandelshtam, M. (2014) Korennye kosmopolity. Ekologicheskaia zashchita i aktivizm v Sibiri i na Dal'nem Vostoke [Indigenous cosmopolitans. Environmental protection and activism in Siberia and the Far East]. In: Kul'tura Arktiki [Culture of the Arctic]/ ed. by U. A. Vinokurova. Yakutsk, Publ. House of North-Eastern Federal University. 344 p. Pp. 58-77. (In Russ.). 
Bogoiavlenskii, D. (2004) Vymiraiut li narody Severa? [Are peoples of the North dying out?]. Naselenie i obshchestvo, no. 83. August. [online] Available at: http://demoscope.ru/acrobat/ps83.pdf [archived in WebCite] (accessed 08.02.2015).

Bogoiavlenskii, D. (2012) Dannye vserossiiskoi perepisi 2010 [The data of All-Russian population census 2010]. Assotsiatsiia korennykb malochislennykb narodov Severa, Sibiri i Dal' nego Vostoka Rossiiskoi Federatsii [Russian Association of Indigenous Peoples of the North, Siberia and Far East of the Russian Federation] [online] Available at: http://raipon.info/peoples/data-census-2010/datacensus-2010.php [archived in WebCite] (accessed 08.02.2015). (In Russ.).

Boronoev, A. O. (2006) Sibirskii mentalitet kak territorial'no-regional'naia forma sub"ektivnosti [Siberian mentality as territorial and regional forms of subjectivity]. In: Sibirskaia mental'nost' $i$ problemy sotsiokul'turnogo razvitiia regiona [Siberian mentality and the issues of the region's social and cultural development] : Reports and proceedings of All-Russian research-to-practice conference, July 5-6, 2006. Ulan-Ude, East Siberia State University of Technology and Management Publ. Vol. 1. 261 p. Pp. 40-45. (In Russ.).

Dargyn-ool, Ch. K. (2003) Kul'tura kak osnova sotsial'nogo razvitiia regionov Rossii (na primere Tuvy) [Culture as a basis for social development of Russian regions (The case of Tuva)]. Gumanitarnye nauki v Sibiri, no. 3, pp. 40-43. (In Russ.).

Zausaev, V. K. (2014) Dal'nii Vostok Rossii: brosok v globalizatsiiu ili gosudarstvennyi paternalizm? [The Russian Far East: A leap into globalization or state paternalism?]. EKO. Vserossiiskii ekonomicheskii zhurnal, no. 3 (477), pp. 105-114. (In Russ.).

Lamazhaa, Ch. K. (2010) Arkhaizatsiia, traditsionalizm i neotraditsionalizm [Archaization, traditionalism and neotraditionalism]. Znanie. Ponimanie. Umenie, no. 2, pp. 88-93. (In Russ.).

Lamazhaa, Ch. (2011) Tuva mezhdu proshlym i budushchim [Tuva between past and future]. 2nd edn., revised and enlarged. St. Petersburg, Aleteiia Publ. 368 p. (In Russ.).

Martynov, A. S. and Vinogradov, V. G. (1995) Komfortnost' klimata [Climate comfort]. WebAtlas: "Okruzhaiushchaia sreda $i$ zdorov' e naseleniia Rossii " [The environment and health of population in Russia: A web atlas] [online] Available at: http://bio.krc.karelia.ru/misc/atl/ra25a.htm [archived in WebCite] (accessed 08.02.2015). (In Russ.).

Mir zapovednoi prirody Altaia [The world of the Altai's wild nature] (2009): A schoolbook for the $8^{\text {th }}$ and $9^{\text {th }}$ grades / ed. by R. V. Oparin. Gorno-Altaisk; Barnaul, Foundation for the Sustainable Development of Altai ; ARTIKA Publ. 156 p. (In Russ.).

Popkov, Yu. V., Kostiuk, V. G. and Tiugashev, E. A. (2007) Narody Sibiri v sotsiokul'turnom prostranstve Evrazii: tsennostnye predpochteniia i mezhetnicheskie ustanovki [Siberian peoples in the sociocultural space of Eurasia. Value preferences and interethnic attitudes]. Sotsiologicheskie issledovaniia, no. 5, pp. 62-69. (In Russ.).

Rasputin, V. G. (2008) Zemliia u Baikala = Baikal Land [A land by the Baikal = Baikal Land]. Irkutsk, Sapronov Publ. 415 p. (In Russ.).

Rossiia: federal'nye okruga i regiony (geografiia, nedra, istoriia, naselenie, religiia, vlast', ekonomika, sotsial' naia sfera, dostoprimechatel' nosti, strategiia razvitiia) [Russia: Federal districts and regions (geography, mineral resources, history, population, religion, power, economy, social sphere, sights, strategy for development)] (2006/2007) : An encyclopedia / ed. by M. A. Sevruk. $4^{\text {th }}$ edn., revised and enlarged. Moscow, International University "Sodruzhestvo" Publ. 529 p. (In Russ.).

Suslov, V. I. (2014) Imidzhi Sibiri: ekonomika s istoricheskim uklonom [Images of Siberia: Economy from the historical point of view]. Region: ekonomika $i$ sotsiologiia, no. 1 (81), pp. 86-103. (In Russ.).

Tishkov, V. A. (2014) Korennye narody rossiiskoi Arktiki: istoriia, sovremennyi status, perspektivy : doklad na Obshchem sobranii RAN 16 dekabria 2014 g. [Indigenous peoples of Russian Arctic regions: History, contemporary status, prospects : A report at the General meeting of the Russian Academy of Sciences, December 16, 2014]. Institut etnologii $i$ antropologii RAN. December 22. [online] Available at: http://iea-ras.ru/index.php?go=News\&in=view\&id=528 [archived in WebCite] (accessed 08.02.2015). 
Khariuchi, S. N. (2013) VII s"ezd korennykh malochislennykh narodov Severa, Sibiri i Dal'nego Vostoka Rossiiskoi Federatsii: zhizn', zaboty i nadezhdy nashikh narodov (g. Salekhard, 28-29 marta 2013 g.) [The $7^{\text {th }}$ congress of minority indigenous peoples of the Russian North, Siberia and the Far East: Life, cares and hopes of our peoples (Salekhard, March 28-29, 2013)]. Assotsiatsiia korennykb malochislennykh narodov Severa, Sibiri $i$ Dal'nego Vostoka Rossiiskoi Federatsii [Russian Association of Indigenous Peoples of the North, Siberia and Far East of the Russian Federation] [online] Available at: http://raipon.info/about/Doclad.doc.pdf [archived in WebCite] (accessed 8.02.2015). (In Russ.).

Federal'nyi zakon Rossiiskoi Federatsii ot 29 dekabria 2014 g. № 473-FZ «O territoriiakh operezhaiushchego sotsial'no-ekonomicheskogo razvitiia v Rossiiskoi Federatsii» [Federal Law of the Russian Federation No. 473-FZ of December 29, 2014 "On the Territories of Priority Social and Economic Development in the Russian Federation"]. (2014) Rossiiskaia gazeta. Federal issue no. 6571. December 31. [online] Available at: http://rg.ru/2014/12/31/territorii-dok.html [archived in Web Cite] (accessed 08.02.2015).

XIII investitsionnyi forum «Sochi-2014» [The 13th Investment Forum Sochi-2014]. (2014) Pravitel'stvo RF. September 19. [online] Available at: http://government.ru/news/14835/ [archived in WebCite] (accessed 17.01.2015).

Submission date: 12.02 .2015 .

Винокурова Ульяна Алексеевна - доктор социологических наук, кандидат психологических наук, руководитель научно-исследовательского центра циркумполярной цивилизации Арктического государственного института культуры и искусств. Адрес: 677000, Россия, г. Якутск, ул. Орджоникидзе, д. 4. Тел.: +7 (411-2) 42-47-37. Эл. алрес: Uottaah1707@gmail.com

Vinokurova Uliana Alekseevna, Doctor of Sociology, Candidate of Psychology, Head, Research Center of Circumpolar Civilization, Arctic State Institute of Culture and Arts. Postal address: 4 Ordzhonikidze St., 677000 Yakutsk, Russian Federation. Tel.: +7 (411-2) 42-47-37. E-mail: Uottaah1707@gmail.com 